Journal of Applied Veterinary Sciences, 5 (3): 87 - 91 (2020).

ISSN: Online: 2090-3308, Print: 1687-4072

Journal homepage : https://javs.journals.ekb.eg

\title{
Preparation and Evaluation of A Recent Infectious Laryngotracheitis (ILT) Vaccine from A Local Field Isolate \\ Nada A. Fathy ${ }^{1}$, Abd El-Moneam M.M', Ibrahim S², Norhan Nagy Mohamed ${ }^{3}$, Amina A. Radwan ${ }^{3}$, Rafik Hamed Sayed ${ }^{3}$ \\ ${ }^{1}$ Department of Newcastle disease Vaccine Research, Veterinary Serum and Vaccines Research Institute (VSVRI), Agricultural Research Center (ARC), Abbasia, Cairo, Egypt. \\ ${ }^{2}$ Department of Genetic Engineering, Veterinary Serum and Vaccines Research Institute (VSVRI), Agricultural Research Center (ARC), Abbasia, Cairo, Egypt. \\ ${ }^{3}$ Central Laboratory for Evaluation of Veterinary Biologics (CLEVB), Agricultural Research Center (ARC), Abbasia, Cairo, Egypt. \\ "Corresponding Author, Nada A. Fathy, E-mail: nadadl@yahoo.com
}

\begin{abstract}
Infectious laryngotracheitis (ILT) is a respiratory tract disease affecting chickens worldwide. The disease leads to severe production losses due to increased mortality, decreased egg production, and delayed body weight gain, causing enormous economic losses to the poultry industry. ILT is controlled through vaccination with live-modified attenuated vaccines of chicken embryo origin (CEO) and/or the tissue-culture origin (TCO). This study was conducted to develop Specific Pathogenic Free (SPF) eggadapted live attenuated ILT vaccine from the field strain Fayoum_2018 isolated from broilers in Fayoum Province, Egypt in 2018. The isolate Fayoum_2018 with accession number (MN082684) was characterized molecularly as a TCO vaccine related strain. Measurement of immunity in vaccinated chicks employing the potency test revealed that chicks vaccinated with $0.5 \mathrm{ml}$ of prepared ILT vaccine exhibited ELISA with 1905 antibody titer at $2^{\text {nd }}$-week post-vaccination, which was considered an ILT adequate immune response and increased till reach 3497 antibody titer at $6^{\text {th }}$ week post-vaccination. The current work revealed that Fayoum_2018 ILTV egg adapted live attenuated vaccine produced a satisfactory antibodies titer that was efficient in controlling the ILT field infection in Egypt.
\end{abstract}

Keywords: BVDV, CEO, ELISA, ILT, TCO, SPF

\section{Original Article:}

DOI: HTTPS://DX.DOI.ORG/10.21608/JAV $\underline{2020.101927}$

Received : 09 June, 2020.

Accepted : 06 July, 2020.

Published in July, 2020.

This is an open access article under the term of the Creative Commons Attribution 4.0 (CC-BY) International License . To view a copy of this license, visit http://creativecommons.org/licenses/by/4.0/

J. Appl. Vet. Sci., 5(3 ): 87-91.

\section{INTRODUCTION}

Infectious Laryngotracheitis (ILT) is an acute respiratory disease caused by the infectious Laryngotracheitis virus. This virus is a member of subfamily Alphaherpesvirinae (genus Iltovirus) which affects the upper respiratory tract of chickens (Davison, 2010). In 1925, ILT was firstly described by May and Tittsler 1925. After that, the vaccination of chicken was achieved through cloacal injection of birds with the virulent virus (Brandly and Bushnell, 1934). Noteworthy, this was the first effective vaccine developed for a major avian viral disease (Guy and García, 2008). ILT is controlled through vaccination with live-modified attenuated vaccines, the chicken embryo origin (CEO) vaccines and the tissue-culture origin (TCO) vaccines. Generally, CEO vaccines induce better protection than TCO vaccines (Andreasen et al., 1989).
The CEO vaccine revealed top protection by reducing clinical signs and viral replication (PalominoTapia et al., 2019). However, live attenuated ILT vaccines can create latently infected carrier chickens that become a source for the spread of the virus to nonvaccinated flocks. Therefore, it is recommended to use live attenuated ILT vaccines only in endemic areas (Shan-Chia Ou and Joseph Giambrone, 2012).

In the current study, an egg-adapted ILT live attenuated vaccine was prepared from our field strain Fayoum_2018, isolated from Fayoum province. It was molecularly characterized as a TCO vaccine related strain reported to be retained either by the back passage of an attenuated TCO vaccine strain in susceptible nonvaccinated birds or from genetic recombination of two different TCO vaccine strains (Nourhan et al., 2019). 


\section{Preparation and Evaluation of A Recent Infectious Laryngotracheitis}

\section{MATERIALS AND METHODS}

\section{ILT field isolate}

An Egyptian strain of virulent infectious laryngotracheitis virus (ILTV) named Fayoum_2018 with accession number (MN082684) was isolated from Fayoum province and characterized molecularly as a TCO vaccine related strain (Nourhan et al., 2019). For the preparation of a live attenuated ILT vaccine, an adaptation of the Fayoum_18 strain was conducted through several passages on the chorioallantoic membrane (CAM) of embryonated chicken eggs (ECE) inducing typical pock lesions on CAM. The period of the work from July 2019 till March 2020.

\section{Virulent Challenge ILT virus}

A local isolate of ILT virus was supplied by Reference Strain Department, Central Laboratory for Evaluation of Veterinary Biologics (CLEVB), Abbasia, Cairo, Egypt. It had a titer of $\mathbf{1 0}^{\mathbf{3 . 5}} \mathrm{EID}_{\mathbf{5 0}} / \mathrm{ml}$ and used for the challenge of experimentally vaccinated chicken.

\section{Specific Pathogen Free (SPF) Chicken}

A total of 100 susceptible 3-weeks-old SPF chicken were obtained from the SPF Egg Production Farm, Koum Oshein, El-Fayoum, Egypt used to monitor the egg adapted pathogenicity virus and for vaccine evaluation. These SPF chicken were divided into three groups as follows:

- Forty SPF chicken was used to test the pathogenicity of the egg propagated virus.

- Twenty SPF chicken was used for testing the safety of the prepared vaccine.

- Forty SPF chicken was used for assessment of the potency test.

Serum samples were collected from all birds weekly until six weeks post-vaccination and used to measure antibody levels by ELISA.

\section{SPF embryonated chicken Egg (SPF-ECE)}

SPF eggs were obtained from the SPF Egg

Production Farm, Koum Oshein, El-Fayoum, Egypt used for virus propagation and titration.

\section{Stabilizer}

Lactalbumin sucrose stabilizer $\quad(5 \%$ lactalbumin hydrolysate and $2.5 \%$ sucrose) was prepared according to the (OIE 2014) then added to the ILT virus as a stabilizer. This mixture was distributed in sterile neutral glass vials ( $2 \mathrm{ml} /$ vial) and lyophilized.

\section{ILT virus propagation on CAM of SPF Eggs}

ILT virus propagated and titrated on CAM of SPF Eggs. The virus isolate was inoculated on to CAM of SPF Egg for five successive passages. Virus propagation was performed following the procedure mentioned by (OIE, 2014). Briefly, tissue homogenates of the previously collected pooled samples were centrifuged and the supernatant was collected. Ten-fold serial dilutions of the CAMs homogenates into 12-days-old SPF-ECEs were inoculated in 5 SPF- ECEs for each dilution, separately. The inoculated and non-inoculated (i.e., negative control) eggs were incubated at $37^{\circ} \mathrm{C}$.

Meanwhile, all were observed and candled for five days post-inoculation. Thereafter, all the inoculated eggs were opened, CAMs were cut to collect pock lesions areas before pooling and further passage of the virus in ECEs. The pock lesions were detected 5-days post-inoculation followed by titer calculation using the statistical method described by Reed and Muench (Reed and Muench, 1938).

\section{Testing the pathogenicity of the egg adapted ILT virus in susceptible SPF chicken}

The egg adapted virus was inoculated in 30 susceptible 3-weeks-old SPF chicken via the intratracheal route with $100 \mu$ l of $10^{3.5} \mathrm{EID}_{50}$ of the isolated virus. Ten susceptible SPF chicken was used as control non-inoculated (Guy et al., 1990). Birds were scored for clinical signs for 2-10 days post-inoculation.

\section{Evaluation of the egg adapted ILT vaccine (Quality control) Sterility}

Random samples of the lyophilized vaccine were inoculated separately into plates of nutrient agar, Sabouraud dextrose agar, thioglycolate medium and mycoplasma medium for bacterial contamination (Code of Federal Regulations USA, 2017). The lyophilized vaccine was also examined for the presence of extraneous viruses other than ILT.

\section{Safety test}

A quantity of vaccine virus equivalent to not less than 10 doses was administered to each of twenty SPF chickens by intra-tracheal inoculation. After that, the chickens were observed daily for 21 days. (OIE, 2014)

\section{Potency test}

Infectivity of live ILT virus vaccine is tested by titration in ECEs as follow:

Ten-fold serial dilutions between $10^{-1}$ and $10^{-7}$ of each passage (5 passages) were prepared from the vaccine in sterile PBS, $\mathrm{pH} 7.2$ containing antibiotic.

The dilutions between $10^{-4}$ and $10^{-7}$ were inoculated into 10-12 days-old SPF-ECEs via CAM (5 eggs/dilution, $0.2 \mathrm{ml} / \mathrm{egg}$ ). These eggs were incubated at $37^{\circ} \mathrm{C}$ for 7 days, underwent daily examination. Deaths of ECEs occurred during the first 24 hours were disregarded. Embryos died later were examined individually and those survive up to the seventh day of incubation were examined for ILTV lesions (pock like lesion on CAM or thickening of CAM). (OIE, 2014)

\section{Immunogenicity}

Twenty five SPF-chickens, three weeks old were vaccinated with $0.2 \mathrm{ml}$ of the vaccine by intratracheal inoculation route. Besides, fifteen chickens of 
the same age and source were maintained as controls. Serum samples were collected 14-days postvaccination. After that, serum samples were collected every week until the sixth week to screen by ELISA. (OIE, 2014).

\section{A serological assay using Enzyme-linked Immunosorbent assay test (ELISA)}

ILT indirect ELISA test was applied using ID Screen ILT indirect kit from ID.vet ${ }^{\circledR}$

for the quantitative detection of ILT specific antibodies in chicken sera.

\section{RESULTS}

\section{ILT virus propagation on SPF Egg}

ILT virus propagated on CAM of SPF egg showed pock lesions characterized by the thick grey plaques typical for ILTV growth (Fig. 1).

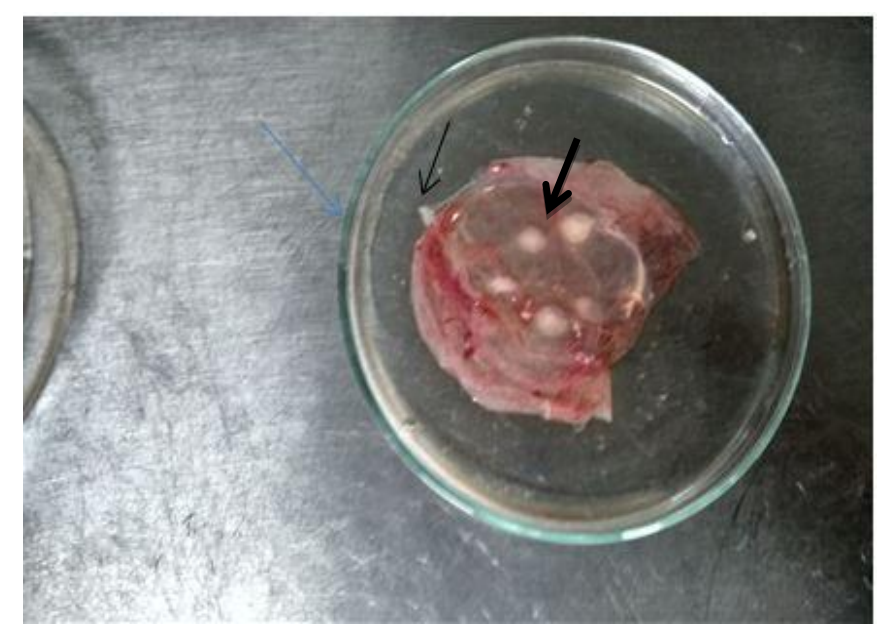

Fig. 1: Chorio-allantoic membranes showing pock lesions characteristic for ILTV virus. The chorioallantoic membrane of 11-days-old embryonated-SPF chicken eggs incubated for five days at $37^{\circ} \mathrm{C}$.

\section{ILT virus titration}

Table 1: illustrated that the virus titer reached 3.5 $\log _{10} \mathrm{EID}_{50} / \mathrm{ml}$ at passage number 5 .

\begin{tabular}{|cc|}
\hline No of passage & $\begin{array}{c}\text { Virus titer } \log _{10} \\
\text { EID }_{50} / \mathrm{ml}\end{array}$ \\
\hline $1^{\text {st }}$ passage & 2.0 \\
\hline $2^{\text {nd }}$ passage & 2.0 \\
\hline $3^{\text {rd }}$ passage & 2.5 \\
\hline $4^{\text {th }}$ passage & 3 \\
\hline $5^{\text {th }}$ passage & 3.5 \\
\hline
\end{tabular}

\section{Pathogenicity test of the propagated virus}

The pathogenicity of the ILT virus propagated on CAM of SPF eggs was conducted on susceptible SPF chicken. Table 2 shows that the $5^{\text {th }}$ passage is a safe virus passage. Intra-tracheal pathogenicity index (ITPI) was calculated and expressed as means. Each bird's clinical signs were reported daily for 14 days as follows: O, normal; 1, respiratory signs; 3, death. Indices were determined by dividing the sum of the scores by the total number of chickens.

Table 2: Pathogenicity test of propagated ILT

\begin{tabular}{|ccccc|}
\hline $\begin{array}{l}\text { Virus } \\
\text { passage }\end{array}$ & $\begin{array}{l}\text { No. of } \\
\text { inoculated } \\
\text { birds }\end{array}$ & $\begin{array}{l}\text { No. of birds } \\
\text { showing } \\
\text { Morbidity } \\
\text { post- } \\
\text { vaccination }\end{array}$ & $\begin{array}{l}\text { No. of birds } \\
\text { showing } \\
\text { mortality } \\
\text { post- } \\
\text { vaccination }\end{array}$ & ITPI* \\
\hline 2 & 10 & 6 & 4 & 0.4 \\
\hline 3 & 10 & 6 & 4 & 0.4 \\
\hline 4 & 10 & 3 & 1 & 0.1 \\
\hline 5 & 10 & 0 & 0 & 0.0 \\
\hline
\end{tabular}

* ITPI: Intra Tracheal Pathogenicity Index

\section{ILT virus vaccine titer after lyophilization}

This lyophilized vaccine was re-titrated in CAM of SPF eggs showing a titer of $10^{3.0} \mathrm{EID}_{50} / \mathrm{ml}$.

\section{Quality control of the prepared ILT vaccine Sterility test}

Bacterial and viral sterility of prepared vaccines proved it is free from bacterial and fungal contamination and extraneous viruses.

\section{Safety test}

On the inoculation of ILT vaccine in susceptible chicken with ten times of the recommended dose none of the vaccinated birds show undesirable symptoms refer to ILT, which proves that the produced vaccine was safe to be used in chicken.

\section{Serological test}

\section{ELISA test}

Table 3: Results of the ELISA test of sera collected from vaccinated and control chickens

\begin{tabular}{|ccc|}
\hline $\begin{array}{l}\text { Weeks post- } \\
\text { vaccination }\end{array}$ & $\begin{array}{c}\text { ILT } \\
\text { Vaccinated } \\
\text { chickens }\end{array}$ & $\begin{array}{c}\text { Control } \\
\text { non- } \\
\text { vaccinated } \\
\text { chickens }\end{array}$ \\
\hline 2 & 1905 & 505 \\
\hline 3 & 3009 & 507 \\
\hline 4 & 3605 & 490 \\
\hline 5 & 3547 & 488 \\
\hline 6 & 3497 & 500 \\
\hline
\end{tabular}




\section{DISCUSSION}

Worldwide, the control of viral diseases in poultry is regulated and relies upon vaccination and high biosecurity standards. There are two types of liveattenuated vaccines utilized and proven to control infectious laryngotracheitis (Vagnozzi et al., 2012). The first type includes vaccines attenuated by multiple passages in embryonated eggs or of chicken embryo origin (CEO). The second type includes vaccines attenuated by multiple passages in tissue culture or of tissue culture origin (TCO). The CEO vaccine has been proven to be effective in producing good protection against the disease (Fulton et al., 2000; Han and Kim, 2003; Rodríguez et al., 2008).

The current study aimed to prepare and evaluate the protection induced by ILTV egg adapted vaccine in SPF chicks. To prepare a live attenuated vaccine master seed virus (MSV), ILTV Fayoum_2018 strain was attenuated by performing five serial passages in embryonated SPF eggs. Testing of the MSV for safety, efficacy and purity was performed, followed by titration in SPF eggs before the preservation of MSV aliquots at $-70^{\circ} \mathrm{C}$ for future use. The virus titer reached $3.5 \log _{10} \mathrm{EID}_{50} / \mathrm{ml}$ at the $5^{\text {th }}$ passage. The obtained virus titer by the 5 th passage, i.e., $3.5 \log _{10} \mathrm{EID}_{50} / \mathrm{ml}$, come in accordance with the titer recommended by OIE for MSV safety testing (OIE, 2018) and acceptable in comparison to internationally manufactured live attenuated ILT vaccines, LTVAX (ISBI spa, Italy), ILT vac (TAD Pharmazeutishes Werk GmbH, Germany), LaryngovacTM (Solvay Animal Health, Inc., USA), and Laryngo-vac (Intervet International B.V., Netherland), which have 3.0, 3.1, 3.5, $3.2 \log \mathrm{EID}_{50} /$ dose virus titer, respectively (Han and Kim, 2003).

The pock lesions of the propagated virus on CAM (Figure 1) appeared typical to ILTV. Evaluation of the prepared vaccine was proven to be sterile (i.e., free from any bacterial, fungal and mycoplasma contaminants and free from extraneous viruses). Also, it was completely safe when inoculated either in the protective dose or in a 10-times-dose showing no adverse effect attributable to the vaccine in agreement with OIE recommendation (OIE, 2014).

Assessment of pathogenicity of the virus isolate used in vaccine preparation was conducted in 3 weeks old SPF chickens by calculating the ITPI. The clinical signs and mortalities exhibited by each bird were scored daily for 14 days. The negative controls exhibited a 0.0 value for ITPI. The virus isolates from each passage (from $2^{\text {nd }}$ till $5^{\text {th }}$ passage) were inoculated intra-tracheal in SPF chicken. However, Fayoum_2018 ILT isolates revealed ITPI values of $0.4,0.4,0.1$, and
0.0 for $2^{\text {nd }}, 3^{\text {rd }}, 4^{\text {th }}$, and $5^{\text {th }}$, respectively as shown in Table 1) attenuation of the virus by serial passaging in ECE for five times. These results come in accordance with a previous study that mentioned ITPI values of ILT vaccine strains ranging from 0.0 to 0.14 and values of 0.2 to 0.82 for high virulence ILTV strains (Guy $\boldsymbol{e} t$ al., 1990). Accordingly, the propagated virus from the $5^{\text {th }}$ passage was used as an MSV for the preparation of the ILT vaccine under test.

Although antibodies to ILTV in chicken serum can be detected by virus neutralization (VN), AGID, and indirect immunofluorescence tests, the ELISA test is very sensitive and possibly the best available test for surveillance of ILTV infection (OIE, 2018). In this study, the assessment of antibodies against ILTV was carried out using a commercial indirect ELISA kit on serum samples collected 2, 3, 4, 5, and 6 weeks postvaccination. All collected sera of vaccinated chickens showed positive results over the kit's 611 Positive/negative cut-off point. Moreover, an ascending increase of the antibody titer represented by 1905 absorbance at the $2^{\text {nd }}$ week post-vaccination to 3497 at the $6^{\text {th }}$ week post-vaccination was obtained, indicating that the vaccine built a strong immune response lasting till the $6^{\text {th }}$ week of immunization.

\section{CONCLUSIONS}

In conclusion, the attenuated live vaccine prepared at this study using the recently isolated and characterized local ILTV isolate Fayoum_2018 with accession number (MN082684), was safe, pure, potent and also capable to induce a strong immune response till the $6^{\text {th }}$ week post-vaccination and appropriate for its use in mass vaccine production.

\section{REFERENCES}

ANDREASEN J.R, GLISSON J.R, GOODWIN M.A, RESURRECCION R.S, VILLEGAS $P$ AND BROWN J. 1989. Studies of infectious laryngotracheitis vaccines: immunity in layers. Avian Dis., 33: 524-530.

Brandly, CA and Bushnell, L.D. 1934. A report of some investigations of infectious laryngotracheitis. Poultry Science, 13, 212-217.

CFR (CODE OF AMERICAN FEDERAL REGULATION-13CFR) USA 2017. Published by the office of the federal register national archives records service, Animals and animal products Ch.111.30-11333.

DAVISON, A.J. 2010. Herpes virus systematics. Veterinary Microbiology, 143, 52-69.

FULTON, R.M., SCHRADER, D.L. AND WILL, M. 2000. Effect of route of vaccination on the prevention of infectious laryngotracheitis in commercial egglaying chickens. Avian Diseases, 44: 8-16. 
GUY J.S., BARNES H.J. AND MORGAN L.M. 1990. Virulence of infectious laryngotracheitis viruses: Comparing modified-live vaccine viruses and North Carolina field isolates, Avian Dis, 34:106-113.

GUY, J. AND GARCÍA, M. 2008. Laryngotracheitis. In YM Saif, A.M. Fadly, J.R. Glisson, L.L. McDougald, L.K. Nolan and D.E. Swayne,(Eds.). Diseases of Poultry 12th Edn. (pp. 137-152). Ames: Blackwell.

HAN, M.G. AND KIM, S.J. 2003. Efficacy of live virus vaccines against infectious laryngotracheitis assessed by polymerase chain reaction-restriction fragment length polymorphism. Avian Diseases, 47: 261-71.

MAY H.G AND TITTSLER R.P .1925. Tracheolaryngotracheitis in poultry. J Am Vet Med Assoc, 67: 229-231.

NOURHAN NAGY, SHERIF MAHMOUD, AMINA RADWAN, RAFIK HAMED, MAHMOUD ABD EL-MONEIM, NADA ADEL, HANAN MOHAMED EL-ZAHED .2019. Isolation and molecular characterization of circulating infectious laryngotracheitis (ILT) virus in Egypt, j.Egypt.vet.med.Assoc 79, no 3. 743 - 759.

OIE MANUAL .2018.Avian Infectious Laryngo-tracheitis

OIE TERRESTRIAL MANUAL. 2014. Chapter 2.3 .3 Avian Infectious Laryngo-tracheitis

PALOMINO-TAPIA V.A, ZAVALA G, CHENG S, AND GARCÍA. M .2019. Long-term protection against a virulent field isolate of infectious laryngotracheitis virus induced by inactivated, recombinant, and modified live virus vaccines in commercial layers. Avian Pathol., 48 (3): 209-220.

REED, L.J. AND MUENCH, H. 1938. "Simple method of estimating 50 percent endpoint", Am. J. Hyg. , 27: 493-499.

RODRI'GUEZ-AVILA, A, I. OLDONI, I., RIBLET, S. M. AND GARCI'A, M. 2008. Evaluation of the protection elicited by direct and indirect exposure to live attenuated infectious laryngotracheitis virus (ILTV) vaccines against a recent challenge strain from the United States. Avian Pathology, 37, $287-$ 292.

How to cite this article:

Nada A. Fathy, Abd El-Moneam M.M, Ibrahim S, Norhan Nagy Mohamed, Amina Radwan, and Rafik Hamed Sayed, 2020. Preparation and Evaluation of A Recent Infectious Laryngotracheitis (ILT) Vaccine From A Local Field Isolate. Journal of Applied Veterinary Sciences, 5(3): 87 - 91.

DOI: HTTPS://DX.DOI.ORG/10.21608/JAVS.2020.101927
SHAN-CHIA OU, JOSEPH J GIAMBRONE .2012 Infectious laryngotracheitis virus in chickens. World J Virol 2012 October 12; 1(5): 142-149

VAGNOZZI, A., ZAVALA, G, RIBLET, S.M., MUNDT, A., GARCIA, M. 2012. Protection induced by commercially available live attenuated and recombinant viral vector vaccines against infectious laryngotracheitis virus in broiler chickens. Avian Pathol. 41, 21-31. 